\title{
DOSSIÊ: RADICALISMOS POLÍTICOS
}

\section{DOSSIER: POLITICAL RADICALISM}

DOI: http://dx.doi.org/10.15448/2178-3748.2016.1.24425

O começo do novo milênio refreou já amplamente as esperanças que a história tivesse chegado ao seu fim, ou seja que a derrota do último grande totalitarismo do século $\mathrm{XX}$ deixasse as portas abertas à construção de uma ordem internacional regida pelos princípios liberais e pelos modelos democráticos representativos. Ao contrário dessas prospecções, esses primeiros dezesseis anos de Século XXI testemunharam, mais uma vez, o ingresso na história mundial do conceito de crise; crise de longo curso e em diferentes dimensões: ideológica, econômica, geopolítica.

Essa crise tomou, com certeza, novas faces a nível internacional - hoje o radicalismo religioso dentro do paradigma de um alegado choque de civilizações ou a instabilidade financeira global - mas provocou, a nível nacional, fenômenos constantes na história do homem: a entrada de novos atores sociais e políticos, a produção de dinâmicas de conflito, a transferência, de uma parte a outra de um mesmo continente ou até de continentes diferentes, de ideias e práticas políticas frequentemente traduzidas segundo os sabores locais, a construção de memórias e discursos funcionais à transmissão dessas experiências. Como em todos os momentos de crise e de confrontação, essas irrupções tomam a forma do radicalismo face à realidade existente e correm o risco de serem encaixadas nas grandes narrativas históricas, diluindo, assim, as características peculiares que as tornam tão ricas do ponto de vista epistemológico mesmo em referência ao fenómenos mais amplos.

O intuito do dossiê temático Radicalismos Políticos é exatamente o de retomar a longa e prolífica linha historiográfica da crise, do conflito e da radicalização no século XX sem solução de continuidade com o novo milênio. Esse objetivo é perseguido através da apresentação de casos de estudo cuja matriz política é condutível às grandes famílias políticas da modernidade - a direita e a esquerda - mas cujas peculiaridades geográficas e identitárias permitem apurar ainda mais o conhecimento das tão diferentes facetas com que essa dicotomia clássica se encarnou nas duas margens do Atlântico.

Embora os casos selecionados respeitem a divisão dos sujeitos entre direita e esquerda, tanto os organizadores como os autores estão conscientes da hibridação que os diferentes sujeitos políticos sofrem em época de convulsões ideológicas e políticas. Dessas hibridações 
há sinais claros nos textos apresentados. $\mathrm{O}$ acento, contudo, é posto no caráter diacrônico dos casos: uma série de experiências surgidas ao longo de todo o século $\mathrm{XX}$, com particular referência às épocas de maior convulsão: os anos trinta e os anos sessenta, mas também nesse breve começo de novo milénio.

$\mathrm{Na}$ frente das direitas, particular destaque é dado ao principal movimento fascista da América Latina, a Ação Integralista Brasileira (AIB). Rodrigo Santos de Oliveira e Michelle Vasconcelos do Nascimento apresentam o processo de construção, por parte da AIB, da própria identidade na contraposição entre valores sociais integralistas e erros ideológicos dos adversários, legitimando, assim, o próprio caráter regenerativo e resolutório da crise nacional. O ímpeto identitário dos integralistas é reforçado pela análise de Alexandre Oliveira e Vinícius Ramos sobre a peculiaridade da AIB como movimento fascista que, à diferença do fascismo italiano, resistiu o mais possível à laicização do Estado, à construção de uma religião civil e à secundarização da religião católica como factor de mobilização das massas.

A ponte entre as duas margens do Atlântico é reconstruída por Pedro Ivo Tanagino que, no seu estudo, apresenta o mito conspiratório da AIB, cujas raízes e utilização como factor de mobilização resultam centrais nos movimentos nacionalistas de massa de entreguerras. Essa diferenciação do fascismo brasileiro face ao modelo original europeu encontra prelúdios nas especificidades doutrinárias dos intelectuais conservadores latinoamericanos face aos europeus. Em particular, Luiz Mário Costa apresenta o trabalho dos primeiros anos do século $\mathrm{XX}$ de dois destacados intelectuais contra-revolucionários: o brasileiro Gustavo Barroso e o português Alfredo Pimenta. O intuito de desmontar a suposta fraternidade intelectual luso-brasileira, tomando como indicador a polêmica entre os dois mestres de pensamento sobre um tema central para as direitas - o Império - cujas dimensões do heroísmo e da missão civilizadora marcam o discurso dessa família política ao longo de toda a sua trajectória de declínio no século XX.

A analise das direitas nas margens lusófonos do Atlântico e na primeira metade do século é acompanhada pela investigação das congêneres e contemporâneas na América hispânica. Em particular, Olga Echeverría apresenta as direitas argentinas e uruguaias perante a consolidação dos regimes fascista e nacional-socialista na Europa. A autora refere, em particular, o efeito de radicalização que o nazi-fascismo exerceu nalgumas dessas direitas latino-americanas, descortinando, assim, aquele processo recorrente de marginalização das facções radicais face às moderadas mais aptas a colaborar com os partidos mainstream do arco da governação. Também nesses casos de estudo, a tônica é posta na diferença e 
particularidade dos sujeitos analisados, sublinhando a contraposição entre a postura interclassista e de massa do partido uruguaio face ao caráter elitista das direitas argentinas.

A radicalização de parte das direitas Hispano-americanas, em particular das camadas juvenis, é retomada por Ernesto Bohoslavsky e Gabriela Gomes, desta vez no contexto das amplas mobilizações civis dos anos sessenta e setenta. Acerca desse período, o foco é habitualmente posto sobre os meios de esquerda (camponeses, operários, intelectuais). Os autores, pelo contrário, oferecem um panorama da juventude estudantil que se radicaliza num sentido nacionalista e anticomunista na Argentina e no Chile entre 1959 e 1973, através de várias organizações, como a famosa Tacuara, antes da instauração das ditaduras militares.

A relação entre ditadura e direitas é abordado por Eduardo Chaves, com a análise da construção da memória de Dercy Furtado, deputada estadual, nos anos Setenta, do partido de suporte ao regime militar brasileiro: a Aliança Renovadora Nacional (ARENA). A dimensão da militância estudantil como da construção da própria imagem revelam facetas interessantes do ingresso e da saída do radicalismo político durante o ciclo de crise, ou melhor de percepção da crise.

$\mathrm{Na}$ frente das esquerdas, as contribuições apresentadas apontam para os três mais importantes períodos de crise dos últimos cem anos: o eclodir do movimento operário entre século XIX e XX, as batalhas sindicais dos anos sessenta e a crise financeira global do século XXI, que afetou duramente os países do Sul. Aqui os sujeitos analisados pertencem principalmente ao meio anarquista na sua alvorada e à extrema-esquerda pós-materialista. $\mathrm{O}$ repertório de mobilização do anarcosindicalismo é apreciado por Luiz Felipe Mundim na França do final do século XIX. O objetivo é reconstruir as origens da mobilização e dos métodos escolhidos para descrever o processo de radicalização que tornará $o$ anarcosindicalismo um ator central nos conflitos sociais do princípio do Século XX. A mesma família política é apresentada por Luciano Telles, cuja análise da revista A Lucta Social descortina os processo de radicalização à esquerda dos operários brasileiros da zona de Manaus e a sua aproximação de classe ao tenentismo, à sombra de reivindicações comuns de justiça social.

A peculiaridade do anarquismo como movimento importante mas à margem da crescente onda comunista no século XX é retomada pelo estudo de Maurício Brum. Dentro da célebre experiência de Salvador Allende no Chile, o autor centra a sua análise do radicalismo de esquerda nos anos Sessenta sobre o único partido chileno que não integrou a Unidade Popular: o Movimento de Esquerda Revolucionária (MIR). O intuito é perceber as razões pelas quais uma organização radical escolhe um determinado posicionamento num momento

Oficina do Historiador, Porto Alegre, EDIPUCRS, v. 9, n. 1, jan./jun. 2016, 
decisivo de crise e as modalidade que emprega nessa luta política marginal. Finalmente, no novo milénio e no contexto da crise econômica global, o enfoque é dado menos a uma presença e mais a uma ausência: o caso de Portugal contemporâneo, pois, é emblemático para se perceber como os efeitos de uma crise em determinados países não se reproduzam em outros. Nesse sentido e postas as condições similares entre países do Sul de Europa, José Santana Pereira analisa a esquerda radical portuguesa e, em comparação com a emergente esquerda populista grega (Syriza) e espanhola (Podemos), explica as razões do fracasso das tentativas de construção de um novo sujeito "populista” também nas margens do rio Tejo.

A radicalização dos movimentos sociais tanto a direita como a esquerda determinada pelas crises é também focalizada por Tatiana Poggi, na dimensão particular do contraste legislativo aos chamados crimes de ódio na Europa ocidental. Nesse sentido, a autora analisa o processo que levou ao reconhecimento e defesa legal dos direitos humanos (civis, políticos e sociais) constantemente ameaçados pelas dinâmicas de conflito.

A variedade temática, geográfica, cronológica e metodológica do número monográfico apresentado é mais que uma escolha, é uma escolha justificada pela necessidade sobre um tema como o dos movimentos políticos e sociais em conflito que merece, há anos, uma atenção crescente pela literatura científica. Como demonstram as resenhas de Tiago Carvalho e Tiago Moreira Ramalho sobre duas recentes obras de relevo acerca desse tema, a interdisciplinaridade e pluralidade é fundamental para satisfazer cada vez mais o caráter cumulativo da ciência.

Por fim, algumas questões de grande relevância para as ciências sociais estão dispostas na entrevista realizada com os investigadores António Costa Pinto (Instituto de Ciências Sociais da Universidade de Lisboa) e André Freire (Centro de Investigação e Estudos de Sociologia do Instituto Universitário de Lisboa). Nela, podemos verificar diferentes caminhos de pesquisas, questões interpretativas e, especialmente, contribuições para temáticas tão urgentes.

Como organizadores, temos a certeza que os trabalhos aqui apresentados são de grande ajuda não só para a investigação comparativa sobre radicalização de movimentos políticos e sociais, mas também para as áreas específicas temáticas, temporais ou regionais. Agradecemos ao corpo editorial da revista Oficina do Historiador, aos autores, pareceristas e entrevistados, por este dossiê temático. Desejamos a todos uma boa leitura!

Odilon Caldeira Neto (UFRGS) Leandro Pereira Gonçalves (PUCRS)

Riccardo Marchi (ISCTE-IUL) 